ГЕРГАНА ПЕТКОВА

ПУ „ПАИСИЙ ХИЛЕНДАРСКИ”

ПЛОВДИВ, БЪЛГАРИЯ

gerganapetkova@uni-plovdiv.bg

https://doi.org/10.17234/9789531755139.23

\title{
ХЪРВАТСКИ МЪЖКИ ЛИЧНИ ИМЕНА, ОБРАЗУВАНИ ОТ ЗОонИМИ
}

\begin{abstract}
Обект на изследване в настоящия текст са хърватските мъжки лични имена, образувани от зооними. Основна цел на изследването е техният пълен списък да бъде представен (включително и всички производни от тях антропоними). Ексцерпираните примери са класифицирани според произхода им и според канонизацията им, т. е. дали са канонизирани само от Католическата църква, само от Православната църква или и от двете. Разглежданите антропоними са част от най-древния пласт на хърватската именна система - лични имена, образувани от наименования на животни и птици, които са били тотемни и се е смятало, че притежават свръхестествени качества. Поради тази причина те са част и от много идиоматични изрази, съдържащи елемент зооним.

Rječnik osobnih imena (Речник на личните имена) от Мате Шимундич е използван като основен източник на информация, а всички вторични източници са представени в библиографията към текста.
\end{abstract}

Ключови думи: хърватско мъжко лично име, зооним, идиом

Обект на изследване в настоящия текст са 45 хърватски мъжки лични имена, образувани от зооними. Основната цел на изследването е пълният списьк на гореспоменатите антропоними да бъде представен (включително и техните варианти). Ексцерпираните примери са класифицирани според техния произход и път на навлизане в хърватската антропонимна система и според моделите, използвани в процеса на образуването на личните имена. Допълнителна класификация е направена на базата на екстралингвистичната информация дали разглежданото лично име е канонично, или не, дали е включено в списъка на светците само от Католическата църква, само от Православната църква, или и от двете.

Като основен източник на информация е използван Rječnik osobnih imena от Мате Шимундич, а всички допълнителни материали, използвани в процеса на изследването, са дадени в приложената към текста библиография.

\section{1. Класификация според изконен произход:}

1.1. Имена от домашен произход: Gavran, Golub, Jastreb, Jelen, Lav, Macan, Medvjed, Slavuj, Sokol, Vuk (10 мъжки лични имена); 


\section{2. Имена от чужд произход:}

А.Старогрьцки: Arhip, Egist, Filip/ Pilip/Vilip, Hipokrat, Hipolit, Leoncij/ Leoncije/Leontij/Leontija/Leontije, Leonid/Leonida, Likoje, Onufrij/ Onufrije, Pulja/ Puljo, Tigran (11 мъжки лични имена);

Б. Латински: Akvilin, Leo, Ovidij/ Ovidije, Urso (4 мъжки лични имена);

В.Немски/ старовисоконемски: Adolf, Bernard/ Bernhard, Bernold, Egon, Hildebrand, Landolf, Leonard, Raul, Rolf/Rudolf, Volfgang/Wolfgang (10 мъжки лични имена);

Г. Английски/ староанглийски: Randolf (1 мъжко лично име);

Д. Френски: Agron (1 мъжко лично име);

Е. Италиански: Colombano/ Kolombano/ Kolumbano, Colombo/ Kolombo/ Kolumbo, Napoleon, Orsat, Paun (5 мъжки лични имена);

Ж. Уелски: Artur (1 мъжко лично име);

3. Турски: Bilbil (1 мъжко лично име);

И. Персийски: Šahin (1 мъжко лично име).

В хърватската антропонимна система ясно се открояват няколко пласта на чуждоезиково влияние вследствие на редица исторически обстоятелства - грьцко, римско/латинско, унгарско, немско и турско (Šimunović 2009: 19-20). Приемането на християнството и използването на каноничните списъци ${ }^{1}$ при кръщаването на новородените е допълнителен екстралингвистичен фактор, който оказва влияние върху оформянето на съвременния облик на хърватската именна система.

Това обяснява големия процент на чужди по произход имена в списъка на ексцерпираните мъжки хърватски антропоними, включени в настоящото изследване.

Тези имена навлизат в хърватската антропонимна система директно от чуждата именна система или чрез език-посредник: Leontij/Leontija/Leontije навлиза директно от старогръцки език, но Leoncij/ Leoncije преминава чрез посредничеството на латински. Други подобни случаи, засвидетелствани при разглежданите примери, където се използва език-медиатор, са: Napoleon (от италиански през френски език), Onufrij/ Onufrije (от старогрьцки през латински и през италиански език), Pulja/ Puljo (от старогръцки през български език), Raul (от старовисоконемски през латински, през френски и през италиански език), Šahin (от персийски през турски език) и Tigran (от старогрьцки през арменски език). Очевидно е, че при голяма част от случаите езикът, използван като посредник, е повече от един.

Горепосочената особеност е причина и за съществуването на следните синонимни гнезда: Golub (хърв.)/ Colombano/Kolombano/ Kolumbano (ит.)/ Colombo/ Kolombo/ Kolumbo (ит.); Lav (хърв.)/ Leo (лат.); Macan (хърв.)/ Egon (нем.);

Включените в каноничните списъци имена са предимно от арамейски, старогръцки и латински произход. 
Medvjed (хьрв.)/ Artur (уелск.)/ Orsat (ит.)/ Urso (лат.); Slavuj (хьрв.)/ Bilbil (тур.); Sokol (хърв.)/ Śahin (перс.); Vuk (хърв.)/ Likoje (стгр.).

Te са се сформирали вследствие на навлизането от различни езици на имена с една и съща етимология и семантика, а на местна почва се открива съответният им хърватски еквивалент.

\section{2. Класификация според модел на образуване:}

2.1. От едноосновни имена без допълнителна деривация (т. е. чрез конверсия):

А. Едноосновни имена, образувани от съществително име: Agron (< pp. héron - „чапла”), Artur (< уелск. arth - ,мечок”), Bilbil (< тур. bülbül - „славей”), Colombano/ Kolombano/ Kolumbano ( $<$ ит. colombo - „гъльб”), Colombo/

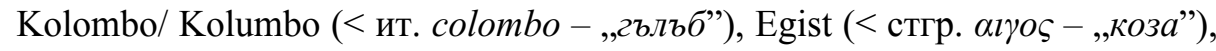
Egon (< ствн. есka - „котка”), Gavran (<хърв. gavran - „гарван”), Golub (< хърв. golub - „гълъб”), Jastreb (< хърв. jastreb - ,ястреб”), Jelen (< хърв. jelen - „елен”), Lav (< хърв. lav - ,льв”), Leo (< лат. leo - ,лъв”), Likoje (< стгр. $\left.\lambda \dot{\kappa} к \varsigma-,, в ъ л \varsigma^{\prime \prime}\right)$, Macan (< хърв. macan - „котарак”), Medvjed (< хърв. medvjed - ,мечок”), Orsat (< ит. orsato - ,меченце”), Paun (< хърв. paun -

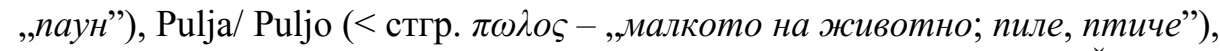
Slavuj (< хърв. slavuj - „славеŭ”), Sokol (< хърв. sokol - „сокол”), Šahin (<

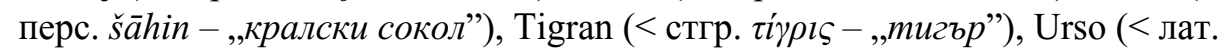
ursus - ,мечок”), Vuk (< хърв. vuk - „,вълк”);

Б. Едноосновни имена, образувани от прилагателно име: Akvilin (< лат. aquilinus - „орлов”), Leoncij/ Leoncije/ Leontij/ Leontija/ Leontije (< стгр. $\lambda \varepsilon \omega v \tau i ́ \varsigma$ - ,львов, лъвски”), Ovidij/ Ovidije (< лат. ovidius - „овчи”).

Почти всички от посочените по-горе примери са образувани директно от апелатив. Изключение правят Agron, Colombano/ Kolombano/ Kolumbano, Colombo/ Kolombo/Kolumbo, Egist, Egon, Leoncij/Leoncije/Leontij/Leontija/Leontije, Orsat, Ovidij/Ovidije и Pulja/Puljo, при които деривацията е базирана на чуждо по произход лично име, което от своя страна е изведено от сыществително нарицателно или прилагателно име.

\section{2. Двуосновни имена:}

А. Двуосновни имена, образувани от номинативна синтагма $(\mathrm{N}+\mathrm{N})$ : Filip/

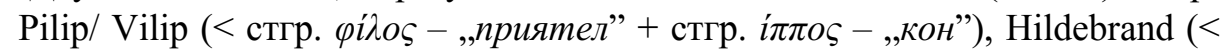
ствн. hildi - „битка, бой” + ствн. branda - „котарак”), Hipokrat (< стгр.

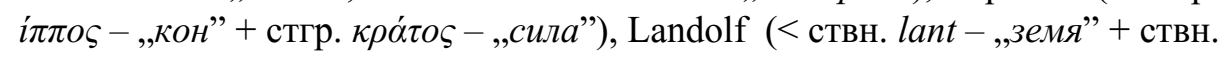

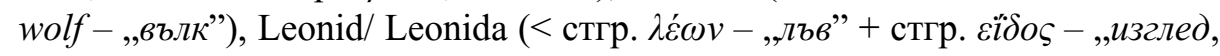
вид, лик”), Napoleon (< ИТИ Napo + ит. leone - „льв”), Randolf (< стангл. rand - ,защиттник” + стангл. wulf-,,вълк”), Raul (< ствн. rād, rāt-,„съвет” + ствн. wolf - ,вълк”), Rolf/ Rudolf (< ствн. hruod, hrod - „слава" + ствн. wolf„вълк”), Volfgang/ Wolfgang (< ствн. wolf- „вълк” + ствн. ganc - ,походка”); 
Б. Двуосновни имена, образувани от атрибутивна синтагма (Adj. $+\mathrm{N})$ : Adolf (< ствн. adal, edel - „благороден” + ствн. wolf - ,вълк”), Bernard/ Bernhard (< ствн. bero - ,мечок” + ствн. harti, herti - ,храбър”), Leonard (< лат. lео ,льв" + ствн. harti, herti - ,храбър, смел”);

В. Двуосновни имена, образувани от обектна синтагма $(\mathrm{V}+\mathrm{N})$ : Arhip $(<$ стгр.

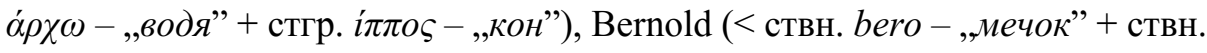
walt, waltan - „владея, управлявам, властвам”), Hipolit (<стгр. ілло - „кон” + стгр. $\lambda v \omega-,, в о д я ")$, Onufrij/ Onufrije (< стгр. óvoৎ - ,магаре; добитък” + стгр. фє́ $\rho \omega-$, ,нося”).

Този модел на образуване на антропоними е най-старият и най-продуктивният в почти всички индоевропейски езици. От ексцерпираните двуосновни хърватски мъжки лични имена, образувани от зооними, по-особен случай представляват антропонимите Napoleon, образуван от корен на съществително собствено и на съществително нарицателно име, и Leonard, където деривацията е извършена чрез комбинация на латински и старовисоконемски по произход апелативи.

\section{3. Класификация на канонизираните хърватски мъжки лични имена, образувани от зооними:}

3.1. Канонизирани от Католическата църква: Adolf, Arhip, Artur, Bernard/ Bernhard, Bernold, Colombano/ Kolombano/ Kolumbano, Colombo/ Kolombo/ Kolumbo, Hildebrand, Landolf, Leonard, Napoleon, Orsat, Raul, Rolf/ Rudolf, Urso, Volfgang/ Wolfgang;

3.2. Канонизирани и от Католическата, и от Православната църква: Akvilin, Filip/ Pilip/ Vilip, Hipolit, Lav, Leo, Leoncij/ Leoncije/ Leontij/ Leontija/ Leontije, Leonid/Leonida, Onufrij/ Onufrije, Tigran.

Изследваните антропоними могат да се разглеждат и от екстралингвистична гледна точка, а именно каква е причината точно определени зооними да послужат като основа за образуването на лични имена. Подобно уточнение е важно за пълната изчерпателност на настоящето проучване.

Почти всички гореспоменати зооними са наименования на тотемни животни и присъстват в митологията и фолклора на много световни народи. Основната причина за избора на конкретно тези птици и животни се крие в тяхната митологична етимология и семантика.

Най-голям е броят на антропонимите (8 мъжки лични имена), изведени от апелатива „вълк”. Митологичната представа за вълка при много народи се свързва с образа на водача, на предводителя на ловната дружина. Олицетворява или родоначалника на племето, или бога на войната (Мифы народов мира, т. 1, 1987: 242).

Седем от антропонимите са образувани от апелатива ,лъв”. Животното е символ на висшата божествена сила, на могыществото, властта, величието, храбростта, благородството и интелигентността (Купър 1993: 74; Мифы народов мира, 
т. 1, 1987: 41). В древността с думата „лъв” са наричали царе, герои и митологични персонажи (Мифы народов мира, т. 1, 1987: 41). При източните народи същата символика има тигъра (Купър 1993: 216), който също така се свързва и с огромна жизнена сила (Мифы народов мира, т. 2, 1988: 511).

Трети по продуктивност от екстралингвистична гледна точка е апелативът „мечка/ мечок” (5 мъжки лични имена). Означава възкресение, защото през пролетта излиза от бърлогата с рожбата си след летаргичен сън; поставя началото на нов цикъл, на нов живот. Например, в скандинавската митология женска мечка на име Атия олицетворява женското начало, а мъжкият Атли - мъжкото (Купър 1993: 131). Подобно на вълка и мечката като тотемно животно се възприема като родоначалник на племето (Мифы народов мира, т. 2, 1988: 128).

Гарванът също има изключително интересна символика. Свързва се с подземния свят, а в митологията се възприема като медиатор между живота и смъртта, между лято и зима, между суша и вода, между мъдрост и глупост, между мъжкото и женското начало (Мифы народов мира, т. 1, 1987: 245). Скандинавският върховен бог, Один, господар и на царството на мъртвите, е съпровождан от два гарвана - Хугин (,мисъл”) и Мунин (,спомен”). Те летели навсякъде и му разказвали всичко, което виждали. И през Античността гарванът е елемент от култовете на богове и герои, свързани с подземното царство (Мифы народов мира, т. 1, 1987: 247).

Почти навсякъде антипод на гарвана се явява гълъбът, който се смята, че помага за преминаването от едно състояние в друго, от един свят в друг. Част е от култа на всички Велики майки и владетелки на небето като символ на възраждането на живота (Купър 1993: 42).

Едно от най-често обожествяваните животни е орелът. Той е олицетворение на върховното божество в митологията на почти всички световни народи (Купър 1993: 150; Мифы народов мира, т. 2, 1988: 258). В древността се е смятало, че орельт може да отлети до сльнцето, да го погледне и да се отъждестви с него. Той е духовното начало у човека, което може да се възвиси до небето (Купър 1993: 151). Соколът и ястребът имат подобна символика (Мифы народов мира, т. 2, 1988: 259). Сокольт се свързва и със стремежът към свобода и надежда за всички, които са под робство - било то морално или духовно (Мифы народов мира, т. 2, 1988: 203).

Другата птица, определяна като царска, е паунът. Свързва се с култа към Дървото на живота и сльнцето (Купър 1993: 156; Мифы народов мира, т. 2, 1988 : 274). Същата е символиката и при елена (Купър 1993: 58), както и при коня, който допълнително се използва като олицетворение на бързата преходност на живота (Купьр 1993: 92).

При останалите зооними митологичната символика е твърде биполярна.

След възникването на християнството, старите езически вярвания, а с тях и всичко, свързано с древните култове, включително и символиката на тотемните животни, е трябвало да бъде претопено. Пътищата за налагане на новата религия 
са два - пълно заклеймяване и демонизиране на старото (вълкът, мечката, гарванът стават олицетворение на Дявола) или неговото асимилиране (гълъбът и орелът се свързват със Светия дух; „стоте очи по перата на пауна представляват всевиждащуата Църква“" (Купър 1993: 156)).

\section{4. Идиоматичните изрази, съдържащи елемент зооним}

Една голяма част от разглежданите зооними, послужили за основа при образуването на изследваните хърватски мъжки лични имена, могат да бъдат открити и в редица фразеологизми и устойчиви сравнения, използвани широко в хърватския език.

1. вълк: gladan kao vuk 'много гладен'; <i> vuk sit $i$ koza cijela, $<i>$ vuk sit $i$ koze na broju 'всеки участник в дадена ситуация е доволен от нейния развой’; jesti kao vuk 'ям много'; morski vuk 'много опитен моряк'; ројео (uјeo) vuk magare (magarca) 'нищо не се е случило'; vuk samotnjak 'самотник, човек, който живее самотно' [HFR]; и пјети (tebi itd.) vuci viju 'някой е бесен, яростен' [НJP];

2. гарван: graktati kao gavran 'силно викам, много говоря'; crn kao gavran 'много черен' [HSRPF]; zloguki gavran 'човек, който говори непрекъснато за надвиснала беда' [HJP];

3. Гълъб: živjeti kao dva goluba, živjeti kao golub i golubica, živjeti kao golubovi 'живея мирно и в сговор' [HSRPF, HFR]; gukni golube ('когато някой е в беда да му се каже незабавно за ситуацията, в която се намира');

4. коза: derati se kao koza 'викам силно' (Рускова-Джерманович 2013);

5. кон: raditi (tegliti) kao konj 'върша тежка работа'; glup kao konj 'много тъп, глуп’ (Рускова-Джерманович 2013);

6. котка/ котарак: obilaziti (motati se i sl.) kao mačak (mačka) oko vruće kaše 'мотая се, нерешителен и претпазлив съм'; premještati kao mačka mlade 'непрекъснато премествам нещзо от едно място на друго’; prebiti (pretući i sl.) kao mačku koga ‘убивам (пребивам) хладнокрьвно някого’ (Рускова-Джерманович 2013);

7. льв: boriti se kao lav ‘сражавам се храбро’; jak kao lav 'много силен’; opasan kao lav 'много опасен'; hrabar kao lav 'много храбьр' (Menac 2007: 128); borben kao lav 'храбър като лъв'; kao lav и kavezu [hodati, šetati i sl.] 'неспокойно, нервно' [HFR];

8. магаре: tvrdoglav kao magarac (magare) 'упорит'; naučiti se (naviknuti se) na što kao magare na batine 'трудно свиквам с нещзо' (Рускова-Джерманович 2013);

9. мечка/ мечок: jak kao medvjed 'много силен' [НJP]; medvjeđa usluga 'ненужна помощ, която след това носи вреда' (Menac 2007: 133); pala muha na medvjeda 'незначителна загуба за някого, който има всичко в изобилие' [HJP]; zaštićen kao medvjed <na Plitvicama> 'напълно защитен' [HSRPF];

10. славей: pjeva kao slavuj ‘пее много хубаво’ [НJP]. 


\section{5. Изводи:}

От ексцерпираните антропоними най-голям е броят на тези, чийто произход е старогръцки. Най-малък е броят на тези, навлезли в хърватската антропонимна система от английски, френски, уелски, турски и персийски език.

От двата основни модела на деривация по-продуктивен се оказва първият, т. е. от един-единствен апелатив. Двадесет и пет от общо двадесет и осемте едноосновни антропонима са образувани от съществително нарицателно име. При двуосновните с най-висока фреквентност е комбинацията от две съществителни имена.

Канонизираните от Католическата църква имена са общо двадесет и пет, а девет от тях са включени в официалните списъци на светците и от Православната църква. Следните имена са неканонични: Agron, Bilbil, Egist, Egon, Gavran, Golub, Hipokrat, Jastreb, Jelen, Likoje, Macan, Medvjed, Ovidij/Ovidije, Paun, Pulja/ Puljo, Randolf, Slavuj, Sokol, Šahin, Vuk.

Всички зооними, послужили за образуването на хърватските мъжки лични имена, които са обект на изследване в настоящия текст, имат дълбока символика, свързана с езически вярвания и ритуали. След възникването на християнството под въздействието на новата религия тяхното старо митологично значение се променя коренно. Това намира отражение и в редица фразеологизми и устойчиви сравнения, които се използват и в съвременния хърватски език. Поради тази причина голяма част от разглежданите антропоними не са канонизирани нито от Католическата, нито от Православната църква.

\section{ИЗПОЛЗВАНИ СЬКРАЩЕНИЯ:}

\begin{tabular}{lll}
\hline арм. - арменски език; & & стгр. - старогръцки език; \\
бълг. - български език; & тур. - турски език; \\
ит. - италиански език; & уелск. - уелски език; \\
лат. - латински език; & фр. - френски език; \\
стангл. - староанглийски език; & хърв. - хърватски език \\
ствн. - старовисоконемски език; &
\end{tabular}

\section{ИНДЕКС НА ХЪРВАТСКИТЕ МЪЖКИ ЛИЧНИ ИМЕНА, ОБРАЗУВАНИ ОТ ЗООНИМИ}

ADOLF - изведено от немското име Adolf със значение „благороден вълк” (< старовисоконемското име Adalwolf < ствн. adal, edel - „благороден” + ствн. wolf - „,вълк”);

AGRON - изведено от френското име Agron (< фp. héron - „чапла”);

AKVILIN (Aquilino (през ит.)) - изведено от лат. aquilinus - „орлов” (< лат. aquila- „орел”);

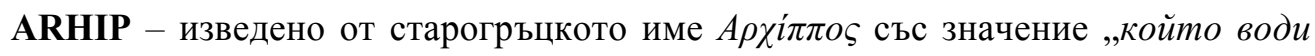

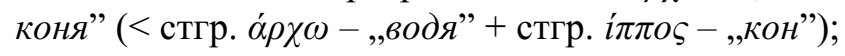

ARTUR (Arturko) - изведено от уелск. arth - ,мечок”; 
BERNARD/ BERNHARD (Bernardin, Bernardino (през ит.), Bernardo (през ит.), Brnadin, Brnardin) - изведено от немското име Bernhard със значение „храбър като мечок” (< ствн. bero - ,мечок” + ствн. harti, herti - „храбър”);

BERNOLD - изведено от немското име Bernnold със значение „властващ като мечок” (< ствн. bero - „мечок” + ствн. walt, waltan - „владея, управлявам, властвам");

BILBIL - изведено от тур. bülbül - „славей”;

COLOMBANO/ KOLOMBAN/ KOLUMBAN - изведено от италианското име Colombano (< ит. colombo - „гълъб”);

COLOMBO/ KOLOMBO/ KOLUMBO - изведено от италианското име Colombo (< ит. colombo - „гълъб");

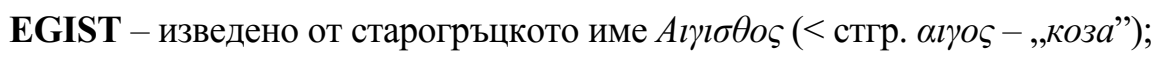

EGON - изведено от немското име Egon (< ствн. ecka - „котка”);

FILIP/ PILIP/ VILIP (Filipac, Filipan, Filipec, Filipenda, Pilipac, Pilipaš, Pilipen-

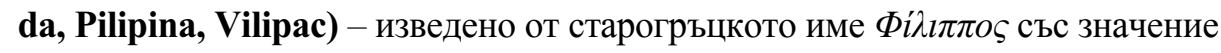

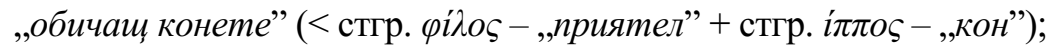

GAVRAN (Gavranić, Gavranko) - изведено от хърв. gavran - „гарван”;

GOLUB (Golubak, Goluban, Golubić) - изведено от хърв. golub - „гълъ б”;

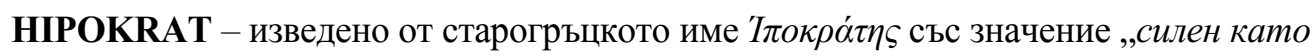

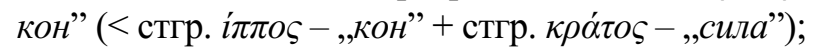

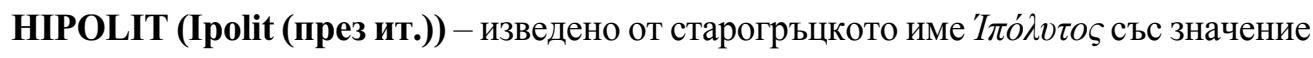

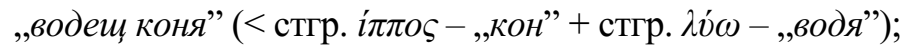

HILDEBRAND (Ildebrando (през ит.)) - изведено от немското име Hildebrand със значение „бие се като котарак” (< старовисоконемското име Hildibrand < ствн. hildi- „битка, бой” + ствн. branda - ,котарак”);

JASTREB - изведено от хърв. jastreb - ,ястреб”;

JELEN (Jelenče, Jelenko) - изведено от хърв. jelen - „елен”;

LANDOLF - изведено от немското име Landolf със значение „земен вълк” (< ствн. lant - ,земя" + ствн. wolf- „вълк");

LAV (Lava, Lave, Lavo, Lavko, Lavomil, Lavoslav) - изведено от хърв. lav - „лъв”;

LEO (Leon, Leonije, Leonika) - изведено от лат. leo - „льв”;

LEONARD/ LEONHARD (Leonardo (през ит.)) - изведено от немското име Leonhard със значение „храбър като лъв” (< лат. lео - ,лъв” + ствн. harti, herti ,- ,рабър, смел");

LEONCIJ/ LEONCIJE - изведено от латинското име Leontius (< старогрьцкото

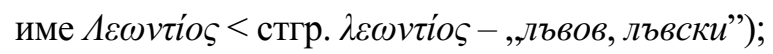

LEONID/ LEONIDA - изведено от старогрьцкото име А $\varepsilon \omega v i \delta \alpha \varsigma$ със значение „с

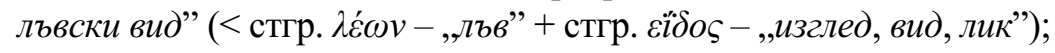




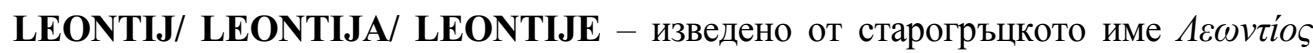

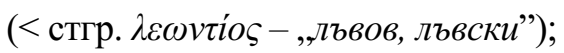

LIKOJE - изведено от стгр. $\lambda \dot{\kappa} \kappa \varsigma$ - ,вълк”;

МАCAN - изведено от хърв. macan - „котарак”;

MEDVJED (Medvjedić, Medvjedina, Medvjetko) - изведено от хърв. medvjed ,мечок";

NAPOLEON - изведено от френското име Napoléon (< италианското име Napoleone < италианското име Napo (< италианското име Iacopo < Iacobus) + ит. leone- „льв");

ONUFRIJ/ ONUFRIJE - изведено от италианското име Onofrio със значение „носещ добитък” (< лат. Onophrius < стгр. óvoৎ - ,магаре; добитък” + стгр. фе́ $\omega-$, ,нося");

ORSAT (Orsato) - изведено от италианското име Orsato (< ит. orsato - „меченце” $<$ ит. оrso - ,мечок");

OVIDIJ/ OVIDIJE (Ovidio (през ит.)) - изведено от латинското име Ovidius (< лат. ovidius - ,овчu” < лат. ovis - ,oвц̧а");

PAUN (Paunac, Paunče, Paunić, Paunko) - изведено от хърв. paun - „,паун” (< ит. paone, pavone - ,nayu”);

PULJA/ PULJO (Pule/ Pulo, Puleta) - изведено от бълг. Пульо (< стгр. $\pi \omega \lambda о \varsigma-$ ,малкото на животно; пиле, птиче”);

RANDOLF - изведено от английското име Randolf със значение „,вълк-зашитник” (< староанглийското име Randwulf< стангл. rand - ,защцитник” + стангл. wulf $-,, 6 ъ л \kappa ")$;

RAUL - изведено от италианското име Raul със значение ,умен като вълк” ( $<$ френското име Raoul < латинското име Rodolphus < старовисоконемското име Radwulf< <твн. rād, rāt- ,cъвет” + ствн. wolf- „,вълк”);

ROLF/ RUDOLF - изведено от немското име Rolf/ Rudolf със значение „славен вълк” (< старовисоконемското Hrodulf < ствн. hruod, hrod - „слава” + ствн. wolf- ,вълк”);

SLAVUJ (Slavujko) - изведено от хърв. slavuj - „славей”;

SOKOL (Sokolić) - изведено от хърв. sokol - „сокол”;

ŠAHIN (Šain, Šajin) - изведено от тур. şahin < перс. šāhin - „кралски сокол”;

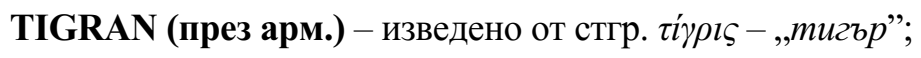

URSO - изведено от лат. ursus - ,мечок”;

VOLFGANG/ WOLFGANG - изведено от немското име Wolfgang със значение „c вълча походка, с походка като на вълк” (< ствн. wolf - „вълк” + ствн. ganc ,походка");

VUK(Vučeta, Vučić, Vuja/Vuje/ Vujo, Vujadin, Vujadinac, Vujadinče, Vujadinko, Vujisav, Vujislav, Vuka, Vukac, Vukadin, Vukailo, Vukajle/Vukajlo, Vukali- 
ca, Vukan, Vukanac, Vukanče, Vukanda, Vukanica, Vukanić, Vukas, Vukašin, Vukča, Vukče, Vukčo, Vukdrag, Vuke, Vukelja, Vukica, Vukić, Vukleta, Vukman, Vukmir, Vuko, Vukobrat, Vukodrag, Vukoica, Vukoja/Vukoje, Vukojica, Vukoman, Vukomanče, Vukomil, Vukomir, Vukosav, Vukoslav, Vukoš, Vukošić, Vukota, Vuksan, Vukša, Vukšan, Vukšica, Vulislav) - изведено

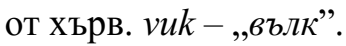

\section{ЛИТЕРАТУРА}

Cooper 1993 = Купър, Джин Кембел. 1993. Илюстрована енцุиклопедия на традициионните символи. София: Петър Берон.

Menac, Antica. 2007. Hrvatska frazeologija. Zagreb: Knjigra.

Mify narodov mira 1987 = Мифы народов мира (Энциклопедия в вдух томах). t. I. 1987. Москва: Советская энциклопедия.

Mify narodov mira 1988 = Мифы народов мира (Энциклопедия в вдух томах). t. II. 1988. Москва: Советская энциклопедия.

Ruskova-Đermanović 2013 = Рускова-Джерманович, Светла. 2013. За отрицателните конотативни значение на някои устойчиви сравнения с компонент названия на домашни жсиотни и птици в български, сръбски и хърватски език. Доклад представен на $3^{\text {rd }}$ Conference for Young Slavists, 25-26 $6^{\text {th }}$ April 2013, Budapest (Hungary) (под печат).

Šimunović, Petar. 2009. Uvod u hrvatsko imenoslovlje. Zagreb: Golden marketing - Tehnička knjiga.

\section{РЕЧНИЦИ}

Fink Arsovski, Željka et al. 2006. Hrvatsko-slavenski rječnik poredbenih frazema. Zagreb: Knjigra. [HSRPF]

Menac, Antica; Fink-Arsovski, Željka; Venturin, Radomir. 2003. Hrvatski frazeološki rječnik. Zagreb: Naklada Ljevak. [HFR]

Šimundić, Mate. 1988. Rječnik osobnih imena. Zagreb: Nakladni zavod Matice Hrvatske.

Vojnov 1996 = Войнов, Михайл et al. 1996. Старогръцко-български речник. София: Отворено общество.

\section{ИНТЕРНЕТСКИ ИЗТОЧНИЦИ}

http://hjp.novi-liber.hr/. Дата на последно посещаване на сайта: 06. 06. 2014. [HJP] www.kurufin.ru Дата на последно посещаване на сайта: 01. 03. 2014. 


\section{SUMMARY}

\section{CROATIAN MASCULINE PERSONAL NAMES, DERIVED FROM ZOONYMS}

The research object of the present text is Croatian masculine personal names, derived from zoonyms. The main research aim is their complete list (including all the variants if these anthroponyms) to be presented. The examples are classified according to their origin and to the very fact if they are canonized by the Church or not.

All the Croatian masculine personal names included in the text are part of oldest level of the Croatian anthroponimic system - personal names, derived from lexemes for animals and birds. These animals and birds used to be totem ones and it is believed that they have extraordinary power. That is why they could be found in a great number of Croatian idioms, containing zoonym. Rječnik osobnih imena by Mate Šimundić is used as a main source of information and all the additional ones are given in the bibliography.

Key words: Croatian masculine personal name, zoonym, idioms 
